\title{
Migration, intermediate inputs and real
}

\section{wages}

\author{
Ivan Pastine and Tuvana Pastine \\ Bilkent University, 06533 Ankara, Turkey
}

\begin{abstract}
To examine the effects of immigration on real wages it is important to focus on the interaction between the labour and intermediate input markets. Immigration can lead to more extensive exploitation of external and internal efficiencies in other input markets, resulting in higher real wages in the destination country.
\end{abstract}

\section{Keywords}

Migration, wage, increasing returns to scale

\section{INTRODUCTION}

This paper analyses an additional effect of migration by focusing attention on the interaction between the labour market and the markets for other inputs in the production process. Immigration, by affecting total market volume, can alter the terms of exchange between markets and can therefore change the ratio of labour to non-labour input. To underline the potential importance of this effect, a simple model is developed where this interaction is the sole effect of immigration on the real wage.

In addition to the neoclassical 'pure supply' effect, two impacts of immigration on real wages have been analysed previously. Thompson (1984), Neary (1989), Rivera-Batiz (1989) and Quibria (1989) present models where immigration of homogeneous labour can increase the real return to labour by expanding aggregate demand for locally produced, sufficiently labour intensive, non-traded consumer goods, which can lead to an overwhelming augmentation in labour demand. There has also been a concentrated effort to study the effects of immigration by disaggregating the labour market and examining the interactions between the markets for various types of labour. By allowing for a continuum of skill levels, Rauch (1991) shows that immigration of skilled labour can lead to an increase in the average wages of all types of labour, but immigration of unskilled labour drives down the real

\footnotetext{
Address for correspondence:

Faculty of Economics, Bilkent University, 06533 Bilkent, Ankara, Turkey.
} 
wages of both unskilled and skilled labour.

These papers examine the interactions between the labour market and the goods market or the markets for different types of labour. The focus here is on the related issue of the interaction between the labour market and the markets for other inputs. To stress the significance of this issue, this paper emphasizes the potential for immigration to lead to higher real wages. It should be realized, however, that the effect induced by this interaction may be of either sign. By assuming long-run duplicability of resources we abstract from the 'pure supply' effect. We assume migration of homogeneous labour to a small open economy to bypass the two interaction effects which have been previously explored. This leaves a model where the sole wage effect of immigration is through this alternative channel.

\section{THE MODEL}

Consider a small open economy where $n$ perfectly competitive firms, indexed by $i$, each with fixed cost $F$, produce a homogeneous output $Y$ using labour $L$ and an intermediate input $I$ via a production technology which is homogeneous of degree $\lambda<1$

$$
Y_{i}=f\left(L_{i}, I_{i}\right) \quad \forall i=1 \ldots n
$$

This implies that average cost curves have the usual $U$ shape and ensures that firm level factor demand functions are well defined. The world price of $Y$ is normalized to 1 . The firms maximize their individual profits $\pi_{i}$ given by

$$
\pi_{i}=Y_{i}-w L_{i}-q I_{i}-F
$$

where $w$ and $q$ are the prevailing wage and intermediate input price respectively. All firms are identical so the subscript $i$ will be omitted where no confusion will result and subscripts will denote first derivatives. Each firm is small relative to the two input markets, and that it cannot individually influence the market input prices. Therefore, maximization of (2) with respect to $L_{i}$ and $I_{i}$ yields

$$
f_{L}=w \text { and } f_{l}=q
$$

which defines firm level factor demands as functions of $w$ and $q$.

There are three equilibrium conditions for this economy. In the labour market, labour is inelastically supplied and wages adjust so that labour demand is equal to labour supply at the full employment level

$$
\mathscr{L}=n L_{i}
$$

where $\mathscr{L}$ is the aggregate labour supply. In the intermediate input market, $J$ units are supplied by a perfectly competitive industry so the quantity supplied adjusts until there is zero excess supply 


$$
J=n I_{i}
$$

The third equilibrium condition is given by the zero profit condition in the final goods market. Free entry and exit in this market ensures that $n$ will adjust in response to economic profits, so that in equilibrium

$$
Y_{i}-w L_{i}-q I_{i}-F=0
$$

for each firm $i$.

The specification of the intermediate input market is the key to the analysis. Of particular interest is the reaction of intermediate input prices to enlarged aggregate market volume. Consider the case where intermediate input prices decline with enlarged aggregate market volume. The intermediate input is non-traded and produced in a perfectly competitive market where firms have a constant marginal cost $c$ which is equal to the average cost. ' In this sector, there are aggregate production externalities depicted as

$$
c=c(J) \quad \text { where } c_{J}<0
$$

Perfect competition in the intermediate input market implies that price is equal to marginal cost

$$
q=c(J)
$$

To examine the effects of immigration in this economy, differentiate (4) and (5) to yield the system

$$
\left.\begin{array}{l}
\mathrm{d} \mathscr{L}=L \mathrm{~d} n+n L_{\iota} \mathrm{d} q+n L_{w} \mathrm{~d} w \\
\mathrm{~d} J=I \mathrm{~d} n+n I_{q} \mathrm{~d} q+n I_{w} \mathrm{~d} w
\end{array}\right\}
$$

Note that $\mathrm{d} J$ and $\mathrm{d} q$ can be eliminated by using the differentiation of $(6)^{2}$

$$
\mathrm{d} q=-\frac{L}{I} \mathrm{~d} w
$$

and the differentiation of (8)

$$
\mathrm{d} J=\frac{1}{c_{J}} \mathrm{~d} q
$$

reducing the system to the following simultaneous equations

$$
\left.\begin{array}{l}
n\left[L_{w^{\prime}}-\frac{L}{I} L_{q}\right] \mathrm{d} w+L \mathrm{~d} n=\mathrm{d} \mathscr{L} \\
{\left[n I_{n^{\prime}}-\frac{L}{I}\left(n I_{q}-\frac{1}{c_{J}}\right)\right] \mathrm{d} w+I \mathrm{~d} n=0}
\end{array}\right\}
$$

Using Crammer's rule (see the Appendix), the real wage effect of immigration of homogeneous labour can be found. After some manipulation it can be reduced to 


$$
\frac{\mathrm{d} w}{\mathrm{~d} \mathscr{L}}=\frac{I}{\frac{L^{2}}{I}\left[n I_{q}-\frac{I}{L} n I_{w}+\left(\frac{I}{L}\right)^{2} n L_{w}-\frac{I}{L} n L_{q}-\frac{1}{c_{J}}\right]}
$$

While the sign of the denominator is not immediately obvious, it can be shown to be positive for any stable economy (see the Appendix). Therefore, for any stable economy

$$
\frac{\mathrm{d} w}{\mathrm{~d} \mathscr{L}}>0
$$

For moderate levels of aggregate production externalities in the intermediate input market, the economy will be stable and immigration will lead to an increase in real wages.

In the long run, the immigration-induced augmentation in the demand for the intermediate input can provoke positive production externalities, inducing a lower marginal cost of producing the intermediate input. Lower marginal costs are then translated into lower input prices which gives rise to an increase in the aggregate demand for labour, and therefore to higher real wages in the destination country. Ceteris paribus, the marginal product of an input follows an inverted $U$ as the quantity of the factor is increased. Although profit maximization ensures that operation at the firm level is in the downward sloping portion of the marginal product curve, no similar argument can be made at the economy level. If the effect of an expanded production set is a decline in the price of the mobile factor's technological complements, the now more abundant factor can be paradoxically relatively scarcer and its price will rise.

In general, an increase in the labour supply will increase aggregate economic activity. This will not only affect the labour market, but also the markets for all other inputs. If expanded demand for non-labour inputs alters their price this will in turn influence the labour market. A decrease (increase) in the price of other inputs will increase (decrease) the profits of the firms which produce the final goods. This will influence the firms' entry decision which will alter the aggregate demand for labour and, therefore, real wages.

\section{CONCLUSIONS}

This paper provides a simple framework to demonstrate the potential significance of the interaction between the labour market and other input markets on the total real wage repercussions of migration. This effect on wages may be of either sign, depending on the structure of the intermediate input market. The model developed in this paper demonstrates that under some conditions this effect can overwhelm those previously examined.

The magnitude and sign of the non-labour input interaction effect depends 
on the importance and behaviour of the markets for non-tradable inputs in production. In modern economies, there are whole arrays of such input markets, each of which is likely to respond differently to increased aggregate market volume. It seems likely that inputs with increasing returns to scale $\left(c_{J}\right.$ $<0$ ) would dominate for relatively small economies (yielding the effect demonstrated here), while for larger economies inputs with decreasing returns to scale $\left(c_{j}>0\right)$ would be more important (yielding a similar effect with opposite sign). This, however, is simply an intuitive conjecture. While theory is quite useful in identifying the possible effects of migration, their magnitudes and, in most cases, their signs, must be examined empirically. Israel, a modern economy which has experienced a large and rapid wave of immigration, might provide a useful test case to examine these issues.

Such an examination of migration and real wages is quite complex. It should not only capture the real wage impact of migration through changes in the ratio of labour to non-reproducible inputs (the 'pure supply' effect), but it should also include the consequences of an increase in the supply of one type of labour on the output markets and on the markets for other types of labour. In addition, the interaction between the labour market and the markets for other inputs needs to be analysed. The magnitude and direction of these effects is contingent on the structure of the economy. Modern economies, with their relatively high usage of reproducible inputs, are likely to exhibit high interaction effects.

\section{ACKNOWLEDGEMENTS}

We gratefully acknowledge the suggestions of James Albrecht, Matthew Canzoneri, John Cuddington, Ashok Kotwal, F. William McElroy, Martin Richardson and two anonymous referees. All responsibility for remaining errors and omissions is entirely our own. Ivan Pastine would like to thank the John M. Olin Foundation for its generous financial support.

\section{APPENDIX}

\section{Derivation of equation (13)}

The system of equations (12) can be written as

$$
\left[\begin{array}{cc}
n\left(L_{w^{\prime}}-\frac{L}{I} L_{q}\right) & L \\
n I_{w^{\prime}}-\frac{L}{I}\left(n I_{q}-\frac{1}{c_{J}}\right) & I
\end{array}\right]\left[\begin{array}{c}
\mathrm{d} w \\
\mathrm{~d} n
\end{array}\right]=\left[\begin{array}{l}
1 \\
\\
0
\end{array}\right] \mathrm{d} \mathscr{L}
$$

and the Jacobian $\nabla$ of the coefficient matrix is given by 